in SSc, but in lunate bone in RA pts. According to the MCP joints, the highest synovitis score was found on the second finger in SSc and RA, highest erosion score also on the second finger in SSc, but on the third finger in RA; The highest bone oedema score was found on the third finger in SSc, and olso on the third and fifth finger in RA pts

Conclusion: MR inflammatory lesions in SSc are less frequent compared to that in RA but still in significant percentage, confirming the need for early detection and aggressive treatment of both, RA and SSc patients with joint involvement References:

[1] Avouac J, Walker UA, Hachulla E, Riemekasten G, Cuomo G, Carreira PE, et al. Joint and tendon involvement predict disease progression in systemic sclerosis: a EUSTAR prospective study. Annals of the rheumatic diseases. 2016;75(1):103-9.

[2] Abdel-Magied RA, Lotfi A, AbdelGawad EA. Magnetic resonance imaging versus musculoskeletal ultrasonography in detecting inflammatory arthropathy in systemic sclerosis patients with hand arthralgia. Rheumatology international. 2013;33(8):1961-6.doi:10.1007/s00296-013-2665-8.

Disclosure of Interests: None declared

DOI: 10.1136/annrheumdis-2020-eular.5001

\section{AB1131 STATISTICAL PROCESS CONTROL AND PROCESS MAPPING QUANTIFY THE EFFECTS OF HISTORICAL CHANGES TO THE CONNECTIVE TISSUE DISEASE TESTING ALGORITHM AND IDENTIFY AREAS FOR FUTURE IMPROVEMENT IN A LARGE DIAGNOSTIC IMMUNOLOGY SERVICE}

M. Stevens ${ }^{1}$, N. Proudlove ${ }^{2}$, J. Ball ${ }^{1}$, C. Scott ${ }^{1}{ }^{1}$ Barts Health NHS Trust, Immunology Laboratory, London, United Kingdom; ${ }^{2}$ Alliance Manchester Business School, Manchester, United Kingdom

Background: Pathology test turnaround times (TATs) are a limiting factor in patient flow through rheumatology services. Quality improvement (QI) methodologies such as Lean use tools including statistical process control (SPC) and process mapping to study the performance of the whole of a clinical pipeline, expose unnecessary complexity (non-value-adding activity), and streamline processes and staff roles.

Objectives: Understand effects of changes made to CTD testing algorithm over last 12 years by measuring some of the effects on TATs. Model current processes and suggest changes to workflow to improve TAT.

Methods: High-level flow diagrams of the current testing algorithm, and low-level process maps of analyser and staff processes were drawn.

Activity and TATs (working days between report and booking date) for ANA, ENA, DNA and CCP tests were plotted as XmR control charts.

Results: Finding 1: Largest referral laboratory does not currently operate a separate DNA monitoring workstream, resulting in unnecessary ANA and ENA testing (figure 1).
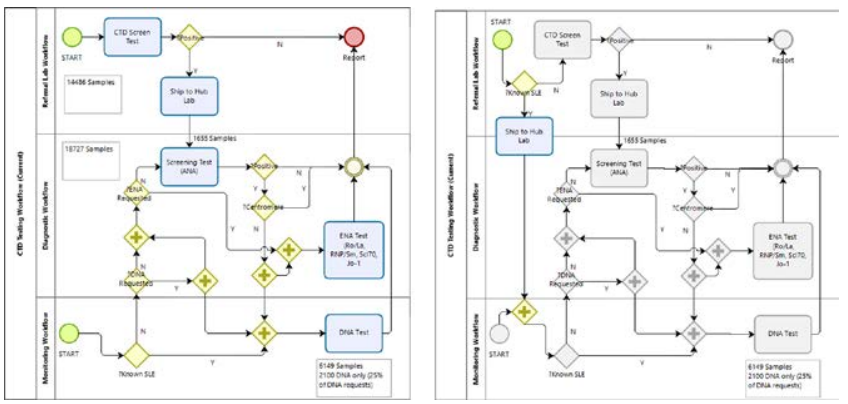

Figure 1. Current testing strategy (left) and suggested improvement (right)

Finding 2: Samples are handed off between 3 different lab benches, each of which may be staffed by a different staff member on a different day, and results processing involves handoff to a further 2 different staff members.

Finding 3: ANA demand is close to capacity, ENA demand exceeds current capacity (table 1).

Table 1. Demand for ANA, ENA and DNA tests, compared to capacity

\begin{tabular}{lccc}
\hline Test & $\begin{array}{c}\text { Median Demand } \\
\text { (tests/ day) }\end{array}$ & $\begin{array}{c}\text { Approx. Capacity } \\
\text { (tests/ day) }\end{array}$ & Notes \\
\hline ANA & 74 & 100 & Close to $80 \%$ recommended by the ILGs \\
ENA & 38 & 36 & *Less capacity than demand!! \\
DNA & 34 & 100 & Plenty \\
\hline
\end{tabular}

Finding 4: Stopping screening DNA requests on ANA result increased the number of DNA tests performed by about 10 samples per day $(30 \%)$, but decreased turnaround time by a similar proportion ( 3.3 to 2.3 days, figure 2 ). It also reduced turnaround times of ANA and ENA tests.

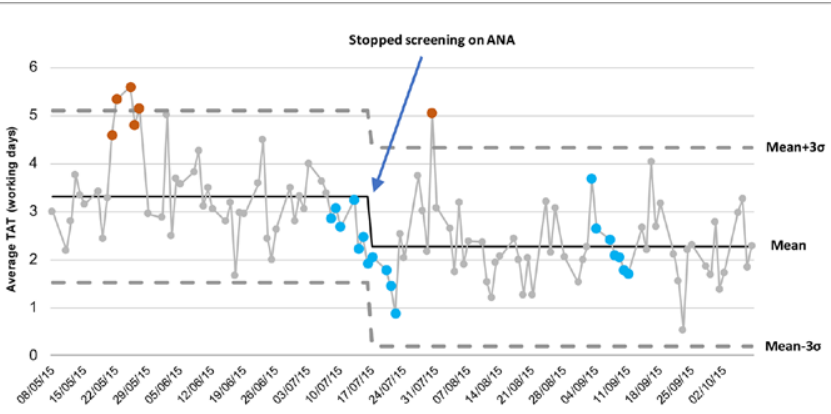

Figure 2. Control chart of average TAT of dsDNA antibodies by request date

Conclusion: Typically for a QI project, the initially simple CTD testing pipeline has accumulated many changes made without consideration of whole system performance, and is now a struggle to run.

Improvement ideas to be explored from this work include:

- Liaising with main referral lab to develop a DNA monitoring workstream to reduce unnecessary ANA and ENA testing

- Reduce handoffs, sample journey around lab analysers, and staff hands-on time by:

- changing ANA test methodology to same as DNA

- creating new staff roles (analyser operators to perform validation/ authorisation steps)

- Create more capacity for ENA testing by increasing the frequency of this test on the weekly rota

- Create more capacity for service expansion by running analysers at weekends (staff consultation required)

- Reduce demand on service by engaging and educating requestors

- Improve TAT for DNA by:

- processing samples the day they are booked in, instead of 1 day later

- auto-validating runs

- ...using control charts to measure improvement

Disclosure of Interests: None declared

DOI: 10.1136/annrheumdis-2020-eular.438

\section{AB1132 EFFECTIVENESS AND SAFETY OF ULTRASOUND- GUIDED FASCIA HYDRORELEASE ON METATARSALGIA WITHOUT SONOGRAPHIC EVIDENCE OF INFLAMMATION IN PATIENTS WITH RHEUMATOID ARTHRITIS.}

M. Suda ${ }^{1,2}$, K. Muranaka ${ }^{3}$, S. Ohde ${ }^{4}$, M. Minoda ${ }^{1}{ }^{1}$ Suwa Central Hospital, Rheumatology, Chino, Japan; ${ }^{2}$ St. Luke's International Hospital, ImmunoRheumatology Center, Chuo City, Japan; ${ }^{1}$ Suwa Central Hospital,

Rheumatology, Chino, Japan; ${ }^{4}$ St. Luke's International University, Graduate School of Public Health, Tokyo, Japan

Background: Patients with rheumatoid arthritis (RA) who have metatarsophalangeal (MTP) joint involvement sometimes complain metatarsalgia without active sonographic inflammation ${ }^{1}$. Treatment of non-inflammatory metatarsalgia in RA is challenging and the pain sometimes lasts for years even though systemic inflammation completely resolves. On the other hand, intervention to fascia has increasingly attracted attention as a management of non-inflammatory pain $^{2}$. Recently, we have invented a new technique called ultrasound-guided fascia hydrorelease (UGFHR), which injects fluid into "stacking fascia" (defined as high echoic and thickened fascia, often adhering to adjacent structures), making it unglued and instantaneously improving fascial pain.

Objectives: This study is aiming for prospective evaluation of effectiveness and safety of UGFHR on metatarsalgia in patients with RA.

Methods: We enrolled consecutive 11 patients with RA who came to rheumatology service in Suwa Central Hospital and satisfied the following inclusion and exclusion criteria:

Inclusion criteria were having at least one MTP joint pain on which the patient has tenderness on the extensor side. 